\title{
Energy Audit on Oil and Gas Industry Facility: Case Study at Field Y, East Kalimantan
}

\author{
Zulfah $^{1, *}$, Annisa Muliahati ${ }^{1, *}$, Eva Fathul Karamah ${ }^{1}$ \\ ${ }^{1}$ Chemical Engineering Department, Engineering Faculty University of Indonesia, Depok 16424, Indonesia
}

\begin{abstract}
This paper discusses energy audit in operating oil and gas production facility in Indonesia by taking a case study at Field Y, East Kalimantan. Energy audit is essential to be carried out in order to identify current rate of efficiency and energy intensity in oil and gas production facility, and extrapolate the data as baseline to recommend potential room for improvement in increasing efficiency. Calculation on efficiency and energy intensity has been performed against main equipments which consumes fuel gas, namely generators and turbo compressors. Data from 2015-2017 were collected to perform the calculation. Calculation results showed that generator thermal efficiency ranges from $13.54 \%-17.45 \%$, which was affected by generator load power itself. The efficiency improves as the load power increases. Meanwhile, compressor thermal efficiency ranged from $28.36 \%-33.79 \%$ depending on process variables and compressed gas volume. Energy intensity calculation result showed the value of $64.554-71.064$ and greenhouse gas emission ranged from $160.48-208.17 \mathrm{kt} \mathrm{CO}_{2}$ eq. From this study, it is identified that improvements to increase efficiency and reduce energy intensity can be made through operating one generator and one compressor, and assessing the use of renewable energy resources to supply power requirement for non-process facilities on site.
\end{abstract}

\section{Introduction}

\subsection{Background and Objectives}

$\mathrm{CO}_{2}$ is one among many components of greenhouse gases (GHG) that is significantly affecting environmental changes such as the rising of land and ocean temperature, as well as climate change, both severely impacting human life. Concentration of $\mathrm{CO}_{2}$ in the atmosphere is rapidly increasing, to which fossil fuel combustion and industrial process holds $78 \%$ contribution in 2000-2010 alone [4].

Indonesia ratified Kyoto Protocol as a commitment to contribute to the global effort of reducing the impact of GHG emission to environment. Kyoto Protocol is an international agreement related to United Nations Framework Convention on Climate Change (UNFCC) signed on December 11, 1997 in Kyoto, Japan. Countries who have ratified this Protocol have committed to collectively reduce emission of $\mathrm{CO}_{2}$ and other 5 greenhouse gases (methane, nitrous oxide, sulphur hexaflouride, hydrofluorocarbon and perfluorocarbon) to $5 \%$ below the 1990 level during the period of 2008 to 2012. In continuation of Kyoto Protocol, in 2015 Conference of Parties (COP) 21 was signed in in Paris. The outcome of the meeting outcome was a legallybinding consensus of 195 countries agreeing to stop the rising of earth's temperature to $2^{\circ} \mathrm{C}$ through $\mathrm{CO}_{2}$ emission reduction.
In 2010, 35\% of GHG emission occurred from energy sector [4]. Oil and gas sector is an energy intensive industry, accordingly oil and gas companies have began finding the right strategy to achieve energy efficiency in their operational activities in order to save energy and contribute to effort of reducing the impact of climate change. Indonesia itself targeted to reduce GHG emission in energy sector to 39 million tones of $\mathrm{CO}_{2}$ or $26 \%$ in year 2030 [1]. In line with this target, energy management system, particularly in energy industry sector, shall be implemented to control energy consumption in order to use energy effectively and efficiently.

Energy required to extract oil and gas is increased due to increasing numbers of wells demanding artificial lift. Besides, reservoir pressure depletion and the maturity of gas reservoir oblige the installation of booster compressor at surface production facility. This causes the increase of both energy use and production cost. At the same time, volatility of oil price forces the industry to seek methods to keep the business profitable, therefore all operational aspects are revisited to identify cost saving rooms. Energy-related cost is identified as the most significant component of the whole operations, therefore energy efficiency method in oil and gas upstream industry is most demanded.

One of strategic objectives issued by Indonesia Ministry of Energy and Mineral Resources (MEMR) is to fulfill domestic energy and fuel by enhancing

\footnotetext{
Corresponding author: zulfah.a@gmail.com and annisamuliahati@gmail.com
} 
efficiency of energy use and reduce emission, indicated by energy intensity and $\mathrm{CO}_{2}$ emission reduction. Energy intensity is a parameter to assess country's energy efficiency and is defined as amount of energy consumption per Gross Domestic Product (GDP). Meanwhile, one of the methods to reduce $\mathrm{CO}_{2}$ emission is by performing energy conservation. In line with this objective, MEMR issued Ministry Decrees Number 14 Year 2012 on Energy Management obliging energy source user and energy user of 6000 tones oil equivalent per year and more to perform energy management by conducting regular energy audit and implementing the audit result.

This research is aimed at mapping the energy consumption and energy intensity in oil and gas industry, particularly the upstream sector through energy auditing. The audit would provide description on $\mathrm{CO}_{2}$ emission contribution from oil and gas upstream sector in Indonesia as well as efficiency on energy use per production unit in barrel oil equivalent (boe). The audit would also provide rooms for improvement to reduce $\mathrm{CO}_{2}$ emission and energy use. As for the industry itself, identified rooms for improvement would be to reduce production cost as the production process will be more efficient and reliability of production equipments, particularly turbo machinery as main equipment, is increased.

\subsection{Profile of Field $Y$}

Field $\mathrm{Y}$ is a central facility to gas and condensate processing, consisting of main facilities of gas receiving manifold platform, compression platform, glycol dehydration platform and oily water treatment platform. The facility was designed to process high, medium and low pressure gas but nowadays production mode is only for medium and low pressure due to reservoir pressure depletion.

Main production equipments at Field $\mathrm{Y}$ are 2 turbo compressors with the capacity of 425 MMSCFD respectively operating in parallel to increase gas pressure from low to export pressure. Prior to being exported, gas is dehydrated by glycol absorption-regeneration. Two generators of $4.5 \mathrm{MW}$ capacity are providing electricity to all production equipments, office and accommodation. Main fuel gas consumer equipments on Field $\mathrm{Y}$ is described in Table 1 below.

Table 1. Main fuel gas consumer equipments.

\begin{tabular}{|c|c|}
\hline Type & Tag Number \\
\hline \multirow{2}{*}{$\begin{array}{c}\text { Turbo } \\
\text { generator }\end{array}$} & G-1 \\
\cline { 2 - 2 } & K-1 \\
\hline $\begin{array}{c}\text { Turbo } \\
\text { compressor }\end{array}$ & K-2 \\
\cline { 2 - 2 }
\end{tabular}

\section{Methodology}

Energy audit was performed by performing calculation on turbo generator and turbo compressor efficiency, energy intensity and greenhouse gas emission using Microsoft Excel. Analysis was carried out against calculation result and rooms for improvement are identified. This method generally can be applied to all oil and gas production facility using main equipment to burn natural gas as fuel.

\subsection{Data Gathering}

Operation data from 1 January 2015 - 31 Desember 2017 was gathered, as displayed on Table 2 and Table 3 below.

Table 2. Generator data.

\begin{tabular}{|c|c|c|}
\hline Data & G-1 & G-2 \\
\hline Load power & Wa1 & Wa2 \\
\hline Fuel gas flow rate & $\mathrm{mfg} 1$ & $\mathrm{mfg} 2$ \\
\hline
\end{tabular}

Table 3.Compressor data.

\begin{tabular}{|c|c|c|}
\hline Data & K-1 & K-2 \\
\hline Pressure suction & $\mathrm{P}_{\mathrm{s} 1}$ & $\mathrm{P}_{\mathrm{s} 2}$ \\
\hline Pressure discharge & $\mathrm{P}_{\mathrm{d} 1}$ & $\mathrm{P}_{\mathrm{d} 2}$ \\
\hline Temperature suction & $\mathrm{T}_{\mathrm{s} 1}$ & $\mathrm{~T}_{\mathrm{s} 2}$ \\
\hline Temperature discharge & $\mathrm{T}_{\mathrm{d} 1}$ & $\mathrm{~T}_{\mathrm{d} 2}$ \\
\hline Fuel gas flow rate & $\mathrm{m}_{\mathrm{fk} 1}$ & $\mathrm{~m}_{\mathrm{fk} 2}$ \\
\hline Process gas flow rate & $\mathrm{w}_{1}$ & $\mathrm{w}_{2}$ \\
\hline Fuel gas flow rate & $\mathrm{mfg} 1$ & $\mathrm{mfg} 2$ \\
\hline
\end{tabular}

Besides the above data, laboratory analysis result on fuel gas and composition on the aforementioned duration was also gathered as reference on Lower Heating Value.

\subsection{Efficiency and Energy Intensity Calculation by Microsoft Excel}

\subsubsection{Fuel gas Lower Heating Value (LHV)}

Fuel gas LHV was calculated with the following equation:

$$
L H V=\Sigma x i . L H V i
$$

where:

xi = component $\mathrm{i}$ fraction
LHVi = LHV of component $\mathrm{i}$ 


\subsubsection{Generator gas turbine efficiency}

Overall efficiency of gas turbine cycle was calculated with the following equation:

$$
E=\frac{W a}{m f \cdot L H v_{f}}
$$

where:

$\mathrm{Wa}=$ actual shaft work, $\mathrm{kW}$

$\mathrm{m}_{\mathrm{f}}=$ fuel gas mass flow, $\mathrm{kg} / \mathrm{s}$

$\mathrm{LHV}=$ lower heating value of fuel, $\mathrm{kJ} / \mathrm{kg}$

\subsubsection{Compressor gas turbine efficiency}

Compressor gas turbine efficiency was calculated by brake power and fuel intake with the following equation:

$$
E=\frac{B p}{m f . L H V f}
$$

where:

$\mathrm{Bp}=$ brake power, $\mathrm{kW}$

$\mathrm{m}_{\mathrm{f}}=$ fuel gas mass flow, $\mathrm{kg} / \mathrm{s}$

$\mathrm{LHV}=$ lower heating value of fuel, $\mathrm{kJ} / \mathrm{kg}$

Compressor shaft power (brake power) was calculated with the following equation:

$$
B p=G p+\text { Mechanical Losses }
$$

where:

$\mathrm{Bp}=$ brake power, $\mathrm{kW}$

$\mathrm{Gp}=$ gas power, $\mathrm{kW}$

Gas power is defined as actual compressor power without considering mechanical losses, calculated with the following equation:

$$
G p=\frac{(w)\left(H_{i s}\right)}{\left(\eta_{i s}\right)(3600000)}
$$

where:

$\mathrm{Gp} \quad=$ gas power, actual compression power excluding mechanical losses, $\mathrm{kW}$

$w=$ produced gas mass flow, $\mathrm{kg} / \mathrm{h}$

$\mathrm{H}_{\mathrm{is}} \quad=$ isentropic head, N.m/kg

$\eta_{\text {is }} \quad=$ isentropic efficiency

Isentropic head and efficency was calculated with the following equations:

$$
\begin{gathered}
I I_{i s}=\frac{(Z \text { avg })(R)\left(T_{1}\right)}{M(k-1) / k}\left[\left(\frac{P_{2}}{P_{1}}\right)^{(k-1) / k}-1\right] \\
\eta_{i s}=\frac{T_{1}\left[\left(\frac{P_{2}}{P_{1}}\right)^{(k-1) / k}-1\right]}{T_{2}-T_{1}}
\end{gathered}
$$

Where:
$\mathrm{H}_{\text {is }} \quad=$ isentropic head, N.m/kg

$Z_{\text {avg }}=$ average compressibility factor

$\mathrm{R} \quad=$ universal gas constant

$\mathrm{M}=$ molecular mass

$\mathrm{T}_{1} \quad=$ inlet temperature, $\mathrm{K}$

$\mathrm{P}_{1} \quad=$ inlet pressure, $\mathrm{kPa}$

$\mathrm{P}_{2}=$ outlet pressure, $\mathrm{kPa}$

$\mathrm{k}=$ isentropic exponent, $\mathrm{Cp} / \mathrm{Cv}$

Value of $\mathrm{k}$ was calculated with the following equation [9]:

$$
k=[1,46-0,16(\gamma-0,55)](1-0,067 \gamma-A T)
$$

where:

$\gamma \quad=$ gas relative density, i.e. ratio of gas molecular weight with molecular weight of air

$\mathrm{A}=0.000272$

$\mathrm{T}=$ temperature, $\mathrm{K}$

Mechanical losses are loss of power due to friction on bearings, seals and speed increasing gears. These losses were calculated by using Scheel's equation below:

$$
\text { Mechanical losses }=0,75(\mathrm{Gp})^{0,4}
$$

\subsubsection{Energy Intensity}

Energy intensity on gas production was calculated with the following equation:

Energy Intensity $=\frac{\text { Anmual export gas volume (boe) }}{\text { Annual fuel gas consumption (boe) }}$

Energy intensity calculation is on annual basis, hence company's performance on energy conservation can be measured.

\subsubsection{Greenhouse gas emission calculation}

Greenhouse gas emission from natural gas combustion as fuel gas on stationer source was calculated as follows, referring to guideline issued by Indonesian Ministry of Environment and Forestry [8]:

$$
\begin{aligned}
& \text { GHG Emission }\left(\frac{\mathrm{kg}}{\mathrm{ygar}}\right)= \\
& \text { Encrgy consumption }\left(\frac{T J}{y \operatorname{sar}}\right) \times \text { Emission Factor }\left(\frac{k g}{T J}\right)
\end{aligned}
$$

GHG emission factor for natural gas fuel on stationer source are as follows:

- $\mathrm{CO}_{2}: 56100 \mathrm{Ton} / \mathrm{GJ}$

- $\mathrm{CH}_{4}: 1 \mathrm{Ton} / \mathrm{GJ}$

- $\mathrm{N}_{2} \mathrm{O}: 0,1$ Ton/GJ

Total GHG quantity of fuel gas result was calculated using with below equation:

$\Sigma k t G R K(k t C O 2 e q)=.k t+(n * k t C H 4)+(n * k t N 20)$ 
where $\mathrm{n}=$ each component Global Warming Potential index.

\section{Result and Discussion}

\subsection{Calculation of Efficiency on Generator and Compressor}

\subsubsection{Generator Efficiency}

Thermal efficiency calculation result on generator G-1 and G-2 is displayed on Figure 1 below.

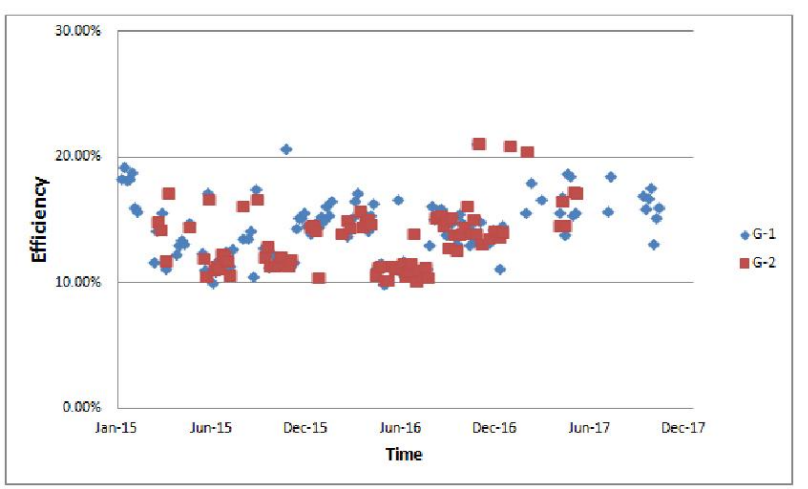

Fig. 1. Generator effiency.

Average generator thermal efficiency ranges from $10-15 \%$, with the details described on Table 4 below.

Table 4. Generator efficiency average.

\begin{tabular}{|c|c|c|}
\hline Year & G-1 & G-2 \\
\hline 2015 & $13.54 \%$ & $15.45 \%$ \\
\hline 2016 & $14.31 \%$ & $15.48 \%$ \\
\hline 2107 & $16.41 \%$ & $17.45 \%$ \\
\hline
\end{tabular}

It is shown that during 2015-2016 period, G-1 and G2 efficiency ranged from 13-15\%, meanwhile in 2017 the value increased significantly to $16.41 \%$ for G-1 and $17.45 \%$ for G-2. This result demonstrated that G-1 \& G2 operated in parallel below optimum load power, which means that both generators operated with low efficiency. Load power increase results in more efficient operation of generator as shown on Figure 2.

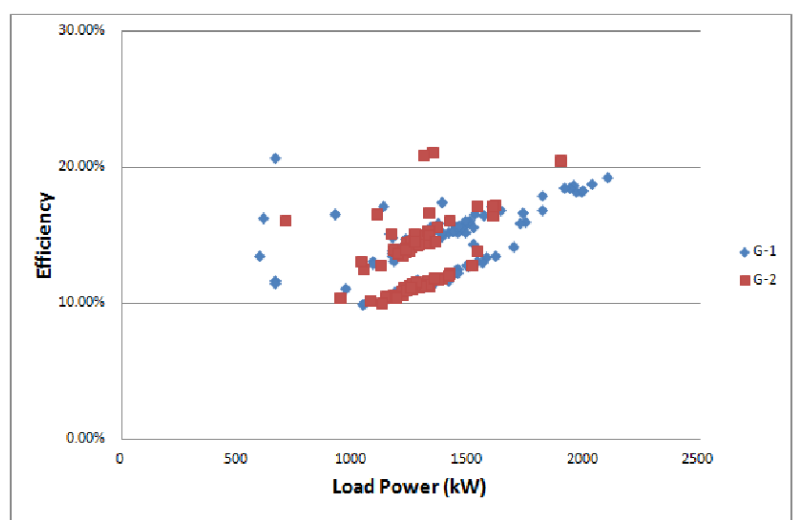

Fig. 2. Generator efficiency and load power correlation.

\subsubsection{Compressor Efficiency}

Compressor thermal efficiency is a ratio of resulted shaft power and fuel gas power. Calculation result of compressor thermal efficiency is shown on Figure 3 below.

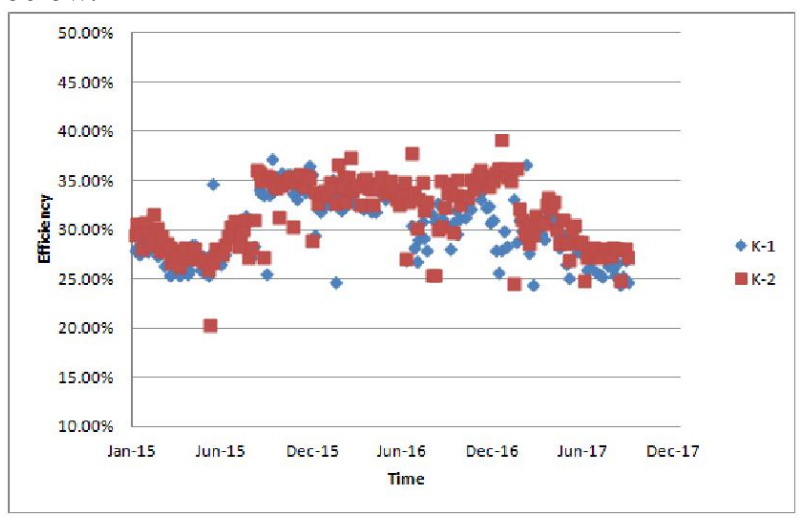

Fig. 3. Compressor thermal efficiency.

Average yearly efficiency details are both compressors is shown on Table 5.

Table 5. Compressor thermal efficiency average.

\begin{tabular}{|c|c|c|}
\hline \multirow{2}{*}{ Year } & \multicolumn{2}{|c|}{ Thermal Efficiency } \\
\cline { 2 - 3 } & K-1 & K-2 \\
\hline 2015 & $30.08 \%$ & $30.36 \%$ \\
\hline 2016 & $32.01 \%$ & $33.79 \%$ \\
\hline 2017 & $28.36 \%$ & $29.87 \%$ \\
\hline
\end{tabular}

Generally, the performance of both compressors was good. Efficiency value varied due to variation on operating condition and produced gas flow rate as shown on Table 6. 
Table 6. Operating Condition

\begin{tabular}{|c|c|c|c|}
\hline \multirow{2}{*}{ Compressor } & Year & $\begin{array}{c}\text { Process Gas } \\
\text { Flow } \\
\text { (MMSCFD) }\end{array}$ & $\begin{array}{c}\text { Suction } \\
\text { Pressure } \\
\text { (barg) }\end{array}$ \\
\hline \multirow{3}{*}{ K-1 } & 2015 & 274.96 & 18.37 \\
\cline { 2 - 4 } & 2016 & 305.34 & 17.30 \\
\cline { 2 - 4 } & 2017 & 254.04 & 17.66 \\
\hline \multirow{3}{*}{ K-2 } & 2015 & 261.97 & 18.31 \\
\cline { 2 - 4 } & 2016 & 307.50 & 17.30 \\
\cline { 2 - 4 } & 2017 & 252.20 & 17.72 \\
\hline
\end{tabular}

It is shown that in 2016, the volume of processed gas was higher than that of 2015 and 2017, hence thermal efficiency of both compressors in 2016 was the highest. Compressor thermal efficiency was affected by shaft power and fuel gas power, defined as power resulted from combustion of each fuel gas volume. Correlation of fuel gas power and processed gas flow rate is shown on Figure 4.

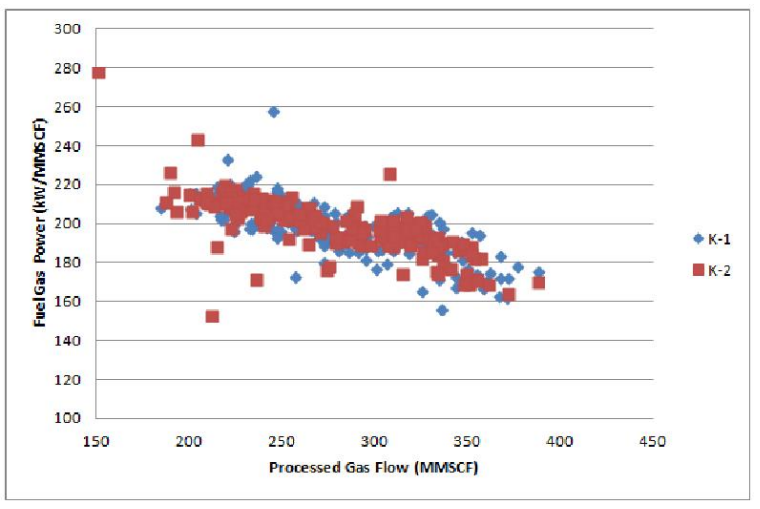

Fig. 4. Fuel gas power and processed gas volume correlation.

Figure 4 above shows that the higher volume of compressed gas, the required power resulted from fuel gas combustion is lower; hence the system is more efficient.

\subsection{Energy Intensity Calculation}

Energy intensity is an indicator of energy consumption to produce one unit of product. This calculation defines energy consumed as energy of fuel gas burned to produce one unit of gas export in annual basis. Energy intensity calculation in Field $\mathrm{Y}$ is shown on Table 7 below.

Table 7. Energy intensity calculation

\begin{tabular}{|c|c|c|c|}
\hline Year & $\begin{array}{c}\text { Fuel Gas } \\
\text { Consumed } \\
\text { (boe) }\end{array}$ & $\begin{array}{c}\text { Processed } \\
\text { Gas } \\
\text { Volume } \\
\text { (boe) }\end{array}$ & $\begin{array}{c}\text { Energy } \\
\text { Intensity }\end{array}$ \\
\hline 2015 & 581,222 & $37,520,368$ & 64.554 \\
\hline 2016 & 631,110 & $42,521,168$ & 67.375 \\
\hline 2017 & 486,554 & $34,575,498$ & 71.064 \\
\hline
\end{tabular}

It is shown that energy intensity value in 2017 was the highest compared to previous 2 years due to less volume of processed gas. Correlation between energy intensity and efficiency is shown on Figure 5.

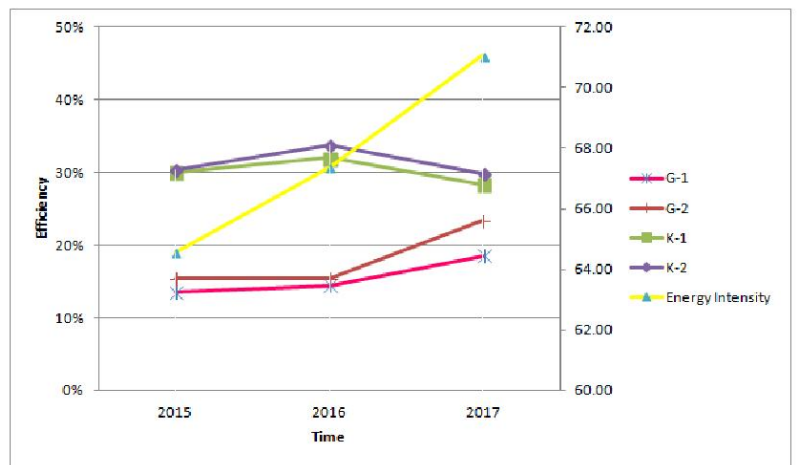

Fig. 5. Efficiency and energy intensity correlation.

It is shown that although generator efficiency increased in 2017, decrease on compressor efficiency has resulted in the high energy intensity of the year.

\subsection{Greenhouse Gas Emission Calculation}

Result on greenhouse gas emission resulted from fuel gas combustion calculation is presented on Table 8 .

Table 8. Greenhouse gas emission calculation result.

\begin{tabular}{|c|c|c|c|}
\hline Year & $\begin{array}{c}\text { Fuel Gas } \\
\text { Consumption } \\
\text { (MSCF) }\end{array}$ & $\begin{array}{c}\text { Energy } \\
\text { Consumption } \\
\text { (TJ) }\end{array}$ & $\begin{array}{c}\text { GHG } \\
\text { Emission } \\
\text { (kt CO } \\
\text { (M) }\end{array}$ \\
\hline 2015 & $3,236,199.91$ & $3,414.19$ & 191.71 \\
\hline 2016 & $3,513,973.68$ & $3,707.24$ & 208.7 \\
\hline 2017 & $2,709,039.56$ & $2,858.04$ & 160.48 \\
\hline
\end{tabular}

It is shown that emission contributed on fuel gas combustion in Field Y ranges from 160.48 to $208.17 \mathrm{kt}$ $\mathrm{CO}_{2}$ eq per year. Fuel gas combustion of compressor contributed $94 \%$ to overall GHG emission per year in Field Y. Correlation on compressor efficiency and GHG emission is shown on Figure 6.

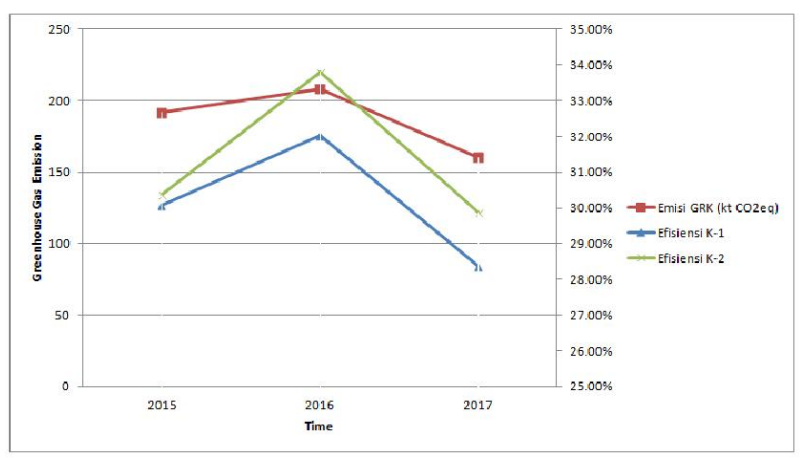

Fig. 6. Greenhouse gas emission and efficiency correlation. 
It is shown that during period of year 2015-2017, emission and efficiency indicated the similar trend. In general, increase on compressor efficiency causes the decrease in specific fuel gas consumption. However, increase of greenhouse gas emission was due to increasing fuel gas consumption during 2015-2016. In the year 2017, although compressor efficiency decreased, fuel gas consumption decreased as well, therefore greenhouse gas emission significantly decreased compared with previous years.

\subsection{Rooms for Improvement}

Based on the above calculation and analysis result, some rooms for improvements were identified to increase equipment efficiency and decrease energy intensity as well as greenhouse gas emission, namely:

1. To operate one generator to increase the load power, as it enhances its thermal efficiency and cause specific fuel gas consumption to decrease.

2. To operate one compressor by considering future gas production rate, so that fuel gas consumption decreases, as along with energy intensity and greenhouse gas emission.

3. To ensure routine maintenance for each equipment and follow up its inspection result to enhancethe performace of the equipment.

4. To use renewable energy source to supply power required by non-process facilities such as accommodation, workshop, office and other supporting facilities. Based on geographical location, solar panel is potential resource to be further studied.

The author would like to acknowledge Hibah PITTA 2018 for publication financial support.

\section{References}

1. Badan Pengkajian dan Penerapan Teknologi. Outlook Energi Indonesia 2016 (2016)

2. J.M. Campbell. Gas Conditioning and Processing, Volume 2: The Equipment Modules (1992)

3. Gas Processors Suppliers Association. Engineering Data Book (1998)

4. IPCC. Climate Change 2014: Synthesis Report (2014)

5. Kementerian ESDM. Kebijakan dan Program Konservasi Energi (2017)

6. Kementerian ESDM. "Peraturan Menteri Energi dan Sumber Daya Mineral Republik Indonesia Nomor 14 Tahun 2012 (2012)

7. Kementerian ESDM. Renstra KESDM 2015-2019 (2015)

8. Kementerian Lingkungan Hidup. Pedoman Penyelenggaraan Inventarisasi Gas Rumah Kaca Nasional (2012)
9. M. Moshfeghian. JM Campbell Tip of the Month. July 2015. http://www.jmcampbell.com/tip-of-themonth/2015/07/how-to-estimate-compressorefficiency/, accessed on 5 December 2017 